\title{
Comparison of the Pharmacokinetic Properties of Vancomycin, LineZOLID, TigECYCLIN, AND DAPTOMYCIN
}

\author{
Kerry S. Estes ${ }^{1}$, Hartmut Derendorf 2,* \\ ${ }^{1}$ PKPDyne, Inc., Gainesville, FL, USA \\ ${ }^{2}$ Department of Pharmaceutics, University of Florida, Gainesville, FL, USA
}

\begin{abstract}
The rapid antibiotic resistance development has created a major demand for new antimicrobial agents that can combat resistant strains such as methicillin-resistant $S$. aureus (MRSA). Until a short time ago, the glycopeptide vancomycin was the only therapeutic choice in this situation. However, in recent years some newer agents with different mechanisms of actions have been added to the arsenal, and more are on the horizon. For a successful therapy it is of vital importance that these compounds are used judiciously and dosed appropriately. The present article reviews the pharmacokinetic properties of vancomycin, linezolid, tigecycline and daptomycin. The first major difference between these compounds is their oral bioavailability. Only linezolid can be administered orally, whereas vancomycin, daptomycin and tigecycline are limited to parenteral use. Once in the body, they show very different disposition. Daptomycin has a very small volume of distribution of $7 \mathrm{~L}$ indicating very little tissue distribution whereas tigecycline has a very large volume of distribution of 350-500 L. Vancomycin and linezolid are in-between with volumes of distribution of approximately 30 and $50 \mathrm{~L}$, close to total body water. However, studies have shown that linezolid shows better tissue penetration than vancomycin. Newer studies using microdialysis, a new technique that allows direct monitoring of unbound tissue levels, support this finding. As far as drug elimination, daptomycin and vancomycin are mainly eliminated into the urine and require dosing adjustments in renally impaired patients, whereas tigecycline is eliminated into the bile and linezolid is metabolized so that in renal patients no dosing adjustments are needed for these compounds. Although the elimination pathways are very different, the resulting half-lives of linezolid, vancomycin, and daptomycin are not greatly different and vary from 4-8 h. Tigecycline, however, has a much longer half-life of up to 1-2 days due to the slow redistribution from tissue binding sites.
\end{abstract}

\section{INTRODUCTION}

Appropriate treatment for serious infections caused by drug resistant Staphylococcus aureus represents a major challenge for clinicians where failure can result in patient mortality. Although newer antibiotic agents have been developed, vancomycin continues to be the most commonly preferred drug for treating serious gram-positive infections involving methicillin-resistant S. aureus (MRSA) and is often administered empirically to patients with serious infections due to methicillin sensitive $S$. aureus (MSSA) prior to microbiological characterization. While numerous reports are available that address vancomycin treatment outcomes in various populations of hospitalized patients, optimized dosing strategies elude consensus at the same time that treatment failure rates are high [1-3]. This report compares pharmacokinetic properties of vancomycin and selected newer agents available for treating patients with serious MRSA infections. The respective pharmacokinetic properties are first presented for each compound and then compared.

\section{VANCOMYCIN}

Vancomycin is indicated for susceptible strains of methicillin-resistant (beta-lactam-resistant) staphylococci [4]. It is indicated for penicillin-allergic patients, for patients who cannot receive or who have failed to respond to other drugs, including the penicillins or cephalosporins, and for infections caused by vancomycin-susceptible organisms that are resistant to other antimicrobial drugs. Vancomycin is indicated for initial therapy when MRSA are suspected, but after susceptibility data are available, therapy should be adjusted accordingly.

Vancomycin is effective in the treatment of staphylococcal endocarditis. Its effectiveness has been documented in other infections due to staphylococci, including septicemia, bone infections, lower respiratory tract infections, skin and skin structure infections. When staphylococcal infections are localized and purulent, antibiotics are used as adjuncts to appropriate surgical measures.

Vancomycin has been reported to be effective alone or in combination with an aminoglycoside for endocarditis caused by $S$. viridans or S. bovis. For endocarditis caused by enterococci (e.g., E. faecalis), vancomycin has been reported to be effective only in combination with an aminoglycoside.

The ability of $S$. aureus to develop drug resistance has been recognized for decades and the incidence of serious MRSA infections continues to rise despite considerable infection control efforts in hospital and community settings [5] The emergence of $S$. aureus 
pathogens with reduced susceptibility to vancomycin in the late 1990s triggered aggressive and costly measures to better control rates of infection and better treat patients with serious drug resistant gram-positive infections. Surveillance investigations demonstrate an increase in $S$. aureus isolates with reduced or "intermittent" sensitivity to vancomycin (VISA). These VISA strains are identified as having in vitro minimum inhibitory concentration (MIC) values to vancomycin of $4-8 \mu \mathrm{g} / \mathrm{mL}[2,6]$.

Additionally, surveillance studies report a consistent increase in mean MIC values for $S$. aureus isolates that are considered susceptible to vancomycin. This increase has been coined "MIC creep" [7]. The clinical significance of increasing MIC within the sensitive range was shown in a study comparing MIC and treatment outcome in patients receiving vancomycin treatment for MRSA bacteremia [8]. Successful bacteria eradication was achieved for $77 \%$ of patients with MIC of $0.5 \mu \mathrm{g} / \mathrm{mL}$ after a mean treatment time of 13 days, while the rate of eradication dropped to only 21 $\%$ after 18 days of vancomycin treatment in patients with MRSA strains characterized as having a MIC of $2.0 \mu \mathrm{g} / \mathrm{mL}$.

The relatively widespread use of vancomycin has been implicated in the emergence of reduced drug sensitivity and its continued use as a first line treatment for MRSA has been questioned in light of MIC creep and high rates of treatment in failure for patients given doses that were considered adequate from microbiological evaluation of bacterial isolates collected from sites of infection [7].

As recently reviewed, vancomycin is among the most studied antibiotics with well described pharmacokinetic properties [9]. Pharmacokinetic studies have characterized vancomycin plasma concentrations with one-, two-, and three-compartment pharmacokinetic models. In patients with normal renal function, the distribution phase ranges from 0.5 to 1 hour, and the $\beta$ elimination half-life usually ranges from 4 to 12 hours. The volume of distribution is generally $0.4-1.0 \mathrm{~L} / \mathrm{kg}$ and protein binding is approximately $50 \%$ [9].

The mechanism of action for vancomycin hinges on the ability of the glycopeptide to complex with Dala moieties during peptidoglycan synthesis and block formation of cell wall structural components. In vitro studies demonstrate that vancomycin exhibits primarily time dependent bactericidal activities and that higher drug concentrations do not correlate with more rapid killing. [10] Several pharmacokinetic/pharmacodynamic parameters were considered for vancomycin dose monitoring and optimization including; time of drug plasma concentration above the MIC within a dosing interval $(t>M I C)$, the ratio of the area under the plasma drug concentration-versus-time curve (AUC) and the MIC (AUC/MIC), and the ratio of the maximum concentration (Cmax) over MIC (Cmax/MIC) [9]. Early studies with a neutropenic mouse thigh infection model indicated that AUC/MIC for vancomycin correlated with drug efficacy, while a clinical study in hospitalized patients with $S$. aureus lower respiratory tract infection found an AUC/MIC ratio $\geq 400$ was associated with significantly better clinical outcome and bacteriological response [11].
Compared to other antibiotics, an efficacious AUC/MIC ratio of 400 for vancomycin is relatively high. However, protein binding and limited penetration to sites of infection must be considered.

Examination of study results in ten mechanically ventilated patients with bronchopneumonia due to MRSA provides a more tangible rationale for targeting serum trough concentrations of $15-20 \mu \mathrm{g} / \mathrm{mL}$ for treating lung infections. The study compared vancomycin concentrations at the presumed site of infection, the epithelium lining fluid obtained during bronchoalveolar lavage, with plasma trough levels. Vancomycin was given intravenously at a daily dose of 30 $\mathrm{mg} / \mathrm{kg}$ in four equal discontinuous infusions administered for a $1 \mathrm{~h}$ period every $6 \mathrm{~h}$ which is similar to the standard dosing of $2 \mathrm{~g}$ over $24 \mathrm{~h}$. The resulting mean trough plasma drug concentration was $16 \mu \mathrm{g} / \mathrm{mL}$. Urea was used as an endogenous marker in this study to quantify the volume of epithelium lining fluid. This approach resulted in highly variable values for amounts of epithelium lining fluid and has also been criticized as overestimating epithelium lining fluid [12]. Interestingly, only 4 of 10 epithelium lining fluid samples contained detectable antibiotic with an average estimated concentration close to the MIC breakpoint of $2 \mu \mathrm{g} / \mathrm{mL}$. Each of the 4 cases with measurable drug in epithelium lining fluid was from a subject with a trough vancomycin serum concentration exceeding 20 $\mu \mathrm{g} / \mathrm{mL}$. In contrast, patients with plasma trough glycopeptides concentrations ranging from approximately 8 to $18 \mu \mathrm{g} / \mathrm{mL}$ had undetectable epithelium lining fluid levels [13].

The factors contributing to vancomycin distribution to target sites of infection in alveolar tissue was addressed by Scheetz who investigated the relationship between vancomycin pulmonary distribution and treatment outcomes in patients with MRSA pneumonia [12]. No known active transport mechanisms for vancomycin across membranes and passive transport is responsible for penetration into tissues that are well perfused such as lungs. Passive diffusion is a function of protein binding, antibiotic molecular weight, lipid solubility, capillary density, capillary and membrane permeability, tissue inflammation, membrane surface area, and oncotic and osmotic gradients. Capillary permeability and oncotic gradients vary with inflammation, and may have an effect on pulmonary disposition of vancomycin. The authors suggested that limited drug access of the bulky hydrophilic moiety may explain why some data suggest concentration dependent action although the mechanism of action for vancomycin should be time dependent. If only $20 \%$ to 30 $\%$ of vancomycin serum concentration is achieved in lung tissue, higher target concentrations may be required to treat pneumonia.

Routine therapeutic drug monitoring reports only total vancomycin concentrations, although protein binding varies and it is generally accepted that only free drug is active. A recent study evaluated total and free drug in a group of 15 patients who were treated by continuous infusion. The study found a wide variation in free to total vancomycin ratios that with a range of $12-100 \%$ and mean of $63.6 \pm 25.8 \%$. The correlation between free and total vancomycin was 
poor. Both intrapatient and interpatient variability were large and no correlation could be made with patients' clinical conditions. The investigators concluded that total vancomycin is not predictive of free vancomycin and recommended routine monitoring of free drug concentrations [14].

In a retrospective study, Jeffres and co-investigators examined the clinical significance of trough vancomycin concentrations that met target levels in patients with health care associated pneumonia due to MRSA isolates [15]. The investigators identified 102 incidents of MRSA with health care associated pneumonia over a 6.5-year period including 32 patients $(31.4 \%)$ who died during their hospitalization. The mean vancomycin trough concentrations did not differ between survivors and treatment failures. The stratification of the vancomycin trough concentrations and AUC values yielded no relationship with hospital mortality. The investigators concluded that aggressive dosing strategies for vancomycin (eg, trough concentrations of $>15 \mu \mathrm{g} / \mathrm{mL}$ ) may not offer any advantage over traditional dose targets of 5 to $15 \mu \mathrm{g} / \mathrm{mL}$. Target doses have shifted upwards during the last decade as reflected in a survey in UK where trough values $>10$ $\mu \mathrm{g} / \mathrm{mL}$ were considered toxic by vast majority of clinicians who used therapeutic drug monitoring [16].

Results of the Jeffres study also highlight the complexity of translating PK/PD principles for vancomycin [15]. The dosing strategy was similar with all patients initially treated with vancomycin in daily doses of $30 \mathrm{mg} / \mathrm{kg}$ in two divided doses during a 24-h period. Vancomycin trough values were identified from serum concentrations collected less than $30 \mathrm{~min}$ before administering the fourth dose (at the onset of steadystate conditions). In addition to the trough values, Jeffres et al estimated total drug exposure $\left(\mathrm{AUC}_{0-24}\right)$ for each patient from the ratio of administered dose versus drug clearance (estimated from creatinine clearance). Considerable variation was identified among the 102 patients given weight based drug doses. The authors noted that even the relationship between measured trough levels and estimated $\mathrm{AUC}_{0-24}$ was not adequate to predict vancomycin exposure from weight based intravenous administration at steady state [15].

Vancomycin was initially associated with clinically significant nephrotoxicity and ototoxicity. Subsequent manufacturing methods eliminated components that were thought to be responsible for high rates of nephrotoxicity observed with the initial product. Several studies examined the relationship between the purified vancomycin product and nephrotoxicity and reported an incidence of 5-7 \% that was considered infrequent and reversible. However the observed rates of nephrotoxicity were highly variable with rates as high as $35 \%$ in patients with vancomycin trough values exceeding $10 \mu \mathrm{g} / \mathrm{mL}$. The high rates were largely attributed to baseline differences in disease severity and concomitant nephrotoxin use across trough groups. Several opinion papers questioned the need to monitor vancomycin levels, because of the perception that there was no relationship between exposure and nephrotoxicity. The consensus ASHP report on therapeutic monitoring of vancomycin in adult patients published in 2009 provided an extensive review of available evidence for nephrotoxicity and ototoxicity and recommended trough concentration monitoring during aggressive vancomycin treatment targeted to achieve concentrations of $15-20 \mu \mathrm{g} / \mathrm{mL}$ [9]. Two studies concluding that a strong relationship exists between the incidence of nephrotoxicity and high vancomycin exposure are described below.

An increased incidence of nephrotoxicity in patients with high $(15-20 \mu \mathrm{g} / \mathrm{mL})$ compared to lower $(<15 \mu \mathrm{g} / \mathrm{mL})$ trough vancomycin concentrations was reported in a retrospective study that included 95 hospitalized patients with MRSA infections [17]. Authors reported nephrotoxcity only occurred in the high trough group with an incidence of $12 \%$ (11 of 63 patients). However, 10 of the 11 patients in the high trough group with nephrotoxicity received concurrent treatment with an aminoglycoside or amphotericin B.

A more recent study identified a strong relationship between the initial trough vancomycin value and the probability of nephrotoxicity in 166 patients [18]. The authors found that higher trough concentrations, especially $>20 \mu \mathrm{g} / \mathrm{mL}$, were associated with an unacceptable risk of nephrotoxicity. The investigators further noted that because the exposure targets for efficacy are rather high for vancomycin (with an $\mathrm{AUC}_{0-24 \mathrm{ss}}$ $/ \mathrm{MIC}=350-400)$, it will be difficult to achieve the exposure endpoint associated with success for serious methicillin-resistant $S$. aureus infections with MICs close to $2 \mu \mathrm{g} / \mathrm{mL}$ without subjecting the patient to a relatively high risk of nephrotoxicity.

A major limitation of many published tissue distribution studies is the fact that they measure biopsies or total tissue concentrations which cannot differentiate between free and bound drug [19, 20]. This limitation can be overcome with the method of microdialysis to directly measure the active, unbound concentrations at the tissue site [21, 22]. Vancomycin tissue concentrations were measured in six diabetic and six nondiabetic patients after cardiac surgery [23]. Vancomycin was administered as a continuous intravenous infusion at an infusion rate of 80 to $120 \mathrm{mg} / \mathrm{h}$. Vancomycin concentrations in soft tissues and plasma were measured by microdialysis on day $8 \pm 4$ after initiation of vancomycin treatment. Vancomycin tissue concentrations in diabetic patients were significantly lower than in nondiabetics. The median vancomycin tissue $_{\text {vanco- }}$ mycin $_{\text {plasma }}$ concentration ratio was 0.1 in diabetic patients and 0.3 in nondiabetics $(P=0.002)$. The study demonstrated that vancomycin penetration into target tissues is substantially impaired in diabetic patients versus nondiabetics. Insufficient tissue concentrations could therefore possibly contribute to failure of antibiotic treatment and the development of antimicrobial resistance in diabetic patients.

\section{LINEZOLID}

Linezolid is the first approved oxazolidinone to be marketed and represents an antibiotic mechanism of action that is characteristic of this class of compounds. The drug inhibits the initiation of the synthesis of bacterial proteins and enzymes, by preventing the formation of the ternary complex at $70 \mathrm{~S}$ ribosomal subunit by an apparent double blockade of both 
the $50 \mathrm{~S}$ and the $30 \mathrm{~S}$ bacterial ribosomal subunits [24]. Linezolid is indicated in the treatment of gram-negative infections [25]: vancomycin-resistant E. faecium infections, including cases with concurrent bacteremia; nosocomial pneumonia caused by $S$. aureus (methicillin-susceptible and -resistant strains), or S. pneumoniae (including multi-drug resistant strains); complicated skin and skin structure infections, including diabetic foot infections, without concomitant osteomyelitis, caused by $S$. aureus (methicillin-susceptible and -resistant strains), S. pyogenes, or $S$. agalactiae; uncomplicated skin and skin structure infections caused by $S$. aureus (methicillin-susceptible only) or S. pyogenes; community-acquired pneumonia caused by $S$. pneumoniae (including multidrug resistant strains), including cases with concurrent bacteremia, or $S$. aureus (methicillinsusceptible strains only).

Early studies demonstrated linear pharmacokinetics with a dose proportional increase in AUC after intravenous doses up to the usual therapeutic dose of 600 mg. Importantly, linezolid demonstrated excellent and complete oral bioavailability that allows ready conversion from intravenous to oral dosing regimens. Linezolid protein-binding is approximately $30 \%$ and the drug is considered to show adequate penetration into tissues at concentrations that are bactericidal [24].

Pharmacokinetic parameters for $600 \mathrm{mg}$ oral doses of linezolid after multiple dosing show Cmax values of approximately $21 \mu \mathrm{g} / \mathrm{mL}$ one hour after administration and a half-life of 5.4 hours [24]. Results from pharmacokinetic studies conducted with linezolid in special populations were recently reviewed [26]. The kidneys function as the primary route of excretion for linezolid with both unchanged parent drug and metabolites measured in urine accounting for most of the dose. However, dose adjustments based on renal function are not indicated based on clinical studies in renally impaired patients. Linezolid AUC increased only $15 \%$ in patients with markedly impaired renal function (creatinine clearance $10-40 \mathrm{~mL} / \mathrm{min}$ ) compared to subjects with normal renal function [27]. Linezolid metabolite levels may increase in patients with severe renal impairment [24].

Although the volumes of distribution of vancomycin and linezolid do not differ by much, it could be shown that linezolid provides a better tissue distribution and particularly lung penetration than vancomycin [28]. In an analysis of a number of previous studies, linezolid demonstrated adequate penetration into lung and other soft issues with sustained concentrations above the minimum inhibitory concentrations for susceptible pathogens, including MRSA, for the majority of the dosing interval. In a study in healthy volunteers, the ability of linezolid to penetrate soft tissues in healthy volunteers was investigated [29]. Ten healthy volunteers were subjected to linezolid drug intake at a dose of $600 \mathrm{mg}$ twice a day for 3 to 5 days. The first dose was administered intravenously. All following doses were self-administered orally. The tissue penetration of linezolid was assessed by use of in vivo microdialysis. The study showed that linezolid penetrates rapidly into the interstitial space fluid of subcutaneous adipose and skeletal muscle tissues in healthy volunteers. On the basis of pharmacokinetic-pharma- codynamic calculations, it could be shown that linezolid concentrations in soft tissues can be considered sufficient to inhibit the growth of many clinically relevant bacteria. The microdialysis technology was then also applied to studies in patients. In a study of inflamed soft tissue and bone of diabetic patients suffering from severe bacterial foot infections, linezolid was administered intravenously twice daily at a dosage of 600 mg [30]. At steady-state conditions, the microdialysis was utilized to sample serially interstitial space fluid from inflamed subcutaneous adipose tissue and bone. The degree of tissue penetration was found to be adequate in diabetic patients suffering from bacterial foot infection complicated by osteomyelitis.

Septic shock and severe sepsis alters fluid dynamics and distribution of body water which could impact drug distribution and dosing. Microdialysis was also employed to show that sepsis did not have an impact on tissue distribution [31]. Sixteen patients with septic shock and eight patients with severe sepsis were compared with matched healthy controls. The results indicated that the severity of sepsis had no substantial effect on the pharmacokinetic profile of linezolid in plasma and in the interstitium of soft tissues. In a similar study in patients with sepsis or septic shock, also microdialysis was utilized to monitor the tissue concentrations of linezolid [32].

Linezolid has limited hepatic metabolism however the pharmacodynamics of the drug include inhibition of monoamine oxidase activity and it is a substrate for the drug transporter ABCB1 which suggest drug interactions could be a clinical concern. Case reports provide limited evidence that caution should be used in co-administering linezolid with drugs that alter serotonergic function (citalopram, duloxetine, meperidine) [26]. Similarly, the synergism between rifampin and linezolid suggested from microbiological studies was not supported by clinical results. The lower than expected CSF linezolid concentrations identified when rifampin was given in combination treatment was attributed to ABCB1 transporter induction associated with rifampin [26].

Linezolid is considered a time-dependent antibacterial agent especially against $S$. aureus. Clinical experience identified targets for $\mathrm{t}>\mathrm{MIC}$ of at least $80 \%$ of the dosing interval as well as a ratio of AUC/MIC $\geq$ 100. These target parameters are consistent with the relatively modest protein binding of linezolid and distribution parameters of the drug [33].

Since its introduction linezolid has maintained excellent activity $[34,35]$. However, some reports have identified increased emergence of drug resistance [3639]. Additionally, some dose limiting toxicity has been found with standard twice daily $600 \mathrm{mg}$ dosing regimens that may limit use of the drug. It was also noted that linezolid could affect its own metabolism as a result of protein synthesis inhibition in mitochondria, and this could lead to high plasma concentrations and increased risk of non-negligible toxicities [26].

\section{TigeCYCLINE}

Tigecycline is a broad-spectrum bacteriostatic, or depending on the microorganism, sometimes bacterioci- 
dal agent that inhibits bacterial protein synthesis by binding to the $30 \mathrm{~S}$ subunit of the prokaryotic ribosome. Tigecycline is the first FDA-approved (2005) representative of a new drug class, the glycylcyclines. Tigecycline shows activity against tetracycline-resistant gram-positive, gram-negative, anaerobe and atypical pathogens [40-45]. It is indicated for the treatment of adults with (1) complicated skin and skin structure infections; (2) complicated intra-abdominal infections; and (3) community-acquired bacterial pneumonia caused by $S$. pneumoniae (penicillin-susceptible isolates), including cases with concurrent bacteremia, $\mathrm{H}$. influenzae (beta-lactamase negative isolates), and $L$. pneumophila [46].

In combination with its broad antimicrobial spectrum, a large volume of distribution ( $\geq 7-10 \mathrm{~L} / \mathrm{kg}$ ) [47-49] and intracellular accumulation [49, 50] are frequently mentioned as providing a rationale for the clinical use of tigecycline. Whether high tigecycline tissue concentrations can be directly correlated to its antimicrobial activity has not yet been determined.

The pharmacokinetic and pharmacodynamic properties of tigecycline have recently be reviewed in detail [51].

It could be shown that tigecycline features linear pharmacokinetics after single doses of 12.5 to $300 \mathrm{mg}$ and at steady state after doses between 25 to $100 \mathrm{mg}$ $\mathrm{q} 12 \mathrm{~h}$ [48]. This is supported by the fact that dose proportionality is observed for maximum plasma concentrations (Cmax) and areas under the concentrationtime curves (AUC). Closer examination of the data from this pharmacokinetic study revealed that there is an increase in the calculated distribution volume (2.8 to $12 \mathrm{~L} / \mathrm{kg}$ ) and half-life (11 to $46 \mathrm{~h}$ ) values with single increasing doses (12.5 - $300 \mathrm{mg})$ [48]. This dose-related behavior indicates non-linear pharmacokinetics which may be explained by concentration-dependent plasma protein and/or tissue binding.

Tigecycline exhibits non-linear plasma protein binding over therapeutic drug concentrations [47-49, 52, 53]. In contrast to the majority of drugs that show non-linear binding, the unbound fraction decreases as the tigecycline concentrations increase $(29 \%$ at 0.1 $\mu \mathrm{g} / \mathrm{mL}$ vs. $11 \%$ at $1.0 \mu \mathrm{g} / \mathrm{mL}$ ) [48]. It has been suggested that this very unusual and atypical binding behavior is linked to the ability of tigecycline to form chelate complexes with multivalent metal ions that bind to plasma proteins. It has also been shown from in vitro experiments that the formation of such tetracycline chelate complexes can result in changes in diffusion rates across membranes or alter binding to plasma proteins $[48,54,55]$. However, it is currently not clear whether this atypical binding behavior has any impact on the pharmacokinetics of tigecycline.

The mean clearance of tigecycline has been reported to range between 0.19 and $0.34 \mathrm{~L} / \mathrm{h} / \mathrm{kg}$ [48, 56, 57]. Although there appears to be some variability, there seems to be no trend with ascending dose. A radiolabel study revealed that the major route of elimination is excretion of unchanged tigecycline in the feces, which accounts for $59 \%$ of the dose [58]. Furthermore, results of this study show that, amongst others, glucuronides and N-acetyl-9-aminominocycline are the main metabolites of tigecycline [58]. Renal elimination of unchanged drug is a minor pathway and accounts for approximately $10-15 \%$ of the dose [48].

Tigecycline has a very large volume of distribution of approximately $7-10 \mathrm{~L} / \mathrm{kg}$ [47-49]. This extremely large volume indicates that tigecycline is extensively bound in the tissues. It was shown that tigecycline could be found in virtually every body fluid, such as bile, epithelial lining fluid, synovia or cerebrospinal fluid and tissue, such as colon, lung and bone [59]. The results of the tissue biopsy studies further revealed that the total concentrations in colon and lung were higher than the corresponding tigecycline plasma levels [59]. This data should be interpreted with great caution, as it was obtained from tissue homogenates and represents a mixture of both free and bound concentrations from different compartments within the tissues (e.g. interstitial fluid, cells, capillaries). These measurements are of limited utility. A better approach is again the use of microdialysis that directly measures the unbound concentrations in the tissues. In a recent study, tigecycline was measured by microdialysis in the interstitial fluid of wound margins versus that of uninfected thigh tissue in adult diabetic patients [53]. The mean values for the unbound concentrations in plasma, thigh, and wound free area under the concentration-time curve from 0 to $24 \mathrm{~h}$ were basically identical. As previously observed in vitro, protein binding was nonlinear, with the percentage of free drug increasing with decreasing serum concentrations, a highly unusual behavior. The data confirmed that one should be very cautious in interpreting total tissue concentrations and relating them to anti-infective activity.

The half-life of tigecycline is variable, reported values range from 15 to $67 \mathrm{~h}[48,49,60,61]$. Since halflife is a secondary pharmacokinetic parameter, variability in this parameter can be attributed to variability in the primary parameters, clearance and volume of distribution. Results from pharmacokinetic studies display relatively consistent clearance values and indicate volume of distribution as the main source for variability, possible due to non-linearity in plasma and/or tissue binding.

It is known that differences in pharmacokinetics can arise between gender and age [62]. In order to evaluate these effects on tigecycline's pharmacokinetics, a study was conducted in 46 healthy volunteers (21 females and 25 males) [57]. In this study, volunteers received a single dose of $100 \mathrm{mg}$ tigecycline that was infused over $60 \mathrm{~min}$. Volume of distributions were found to be approximately 350L for women and 500L for men. However, weight-normalized volumes of distribution were not significantly different. This study demonstrated that there is no difference in the pharmacokinetics, based on age or sex and no dose adjustments are needed.

The effect of renal function on the PK of tigecycline was investigated in a single dose study $(100 \mathrm{mg}$ over $60 \mathrm{~min}$ ). This study was performed in 6 healthy volunteers, 6 patients with severe renal dysfunction, and 8 patients with end-stage renal disease (ESRD) requiring hemodialysis [63, 64]. Results indicate that there was a decrease in the clearance in patients with ESRD. However, while the AUCs and Cmax values were slightly higher in renally impaired patients, it was 
concluded that no dose adjustment is necessary due to the fact that these changes in pharmacokinetics did not affect the tolerability of tigecycline. These findings are not surprising as renal elimination is a secondary pathway along with metabolism to biliary/fecal elimination [58].

Since biliary excretion is one of the main elimination pathways of tigecycline, the effect of hepatic impairment was investigated in 48 subjects (10 patients with mild, 10 patients with moderate and 5 patients with severe hepatic impairment as well as 23 age and weight-matched healthy volunteers) [47]. The results of this study show that there were similar plasma profiles for patients with mild hepatic impairment and healthy individuals. In comparison, in patients with moderate hepatic impairment, the tigecycline clearance was $25 \%$ lower and in patients with severe hepatic impairment, clearance was reduced by $55 \%$. Based on these findings, it is recommended that patients with severe hepatic impairment should receive a reduced maintenance dose of $25 \mathrm{mg}$ BID, whereas the loading dose does not need to be adjusted.

Tigecycline shows little potential for drug interactions [47, 61]. No dosage adjustments are needed when co-administered with warfarin [65].

Tigecycline has almost no oral bioavailability [66]. It is, therefore, administered as a short-term (30 - $60 \mathrm{~min})$ intravenous infusion [47]. A combination of a relatively long half-life and pronounced post-antibiotic effect of tigecycline would generally support an once daily dosing regimen $[67,68]$. However, due to gastrointestinal adverse events, which seem to correlate with peak plasma levels, peak concentrations are kept lower by administering tigecycline as an initial $100 \mathrm{mg}$ loading dose, followed by a $50 \mathrm{mg}$ maintenance dose every 12 hours [48]. For patients with severe hepatic impairment, a reduced maintenance dose of $25 \mathrm{mg}$ BID after an initial $100 \mathrm{mg}$ loading dose is recommended.

\section{DAPTOMYCIN}

Daptomycin is the only member of a class of antibiotics called lipopeptides. It has a mechanism of action by which it interacts with the bacterial cell membrane without entering the cell [69]. This interaction results in very rapid killing of the bacteria. The mechanism of action requires the presence of physiological concentrations of calcium ions. Daptomycin is bacteriocidal and active against gram-positive bacteria.

Daptomycin is indicated for (1) complicated skin and skin structure infections (cSSSI) caused by susceptible isolates of the gram-positive microorganisms. Combination therapy may be clinically indicated if the documented or presumed pathogens include gramnegative or anaerobic organisms; and (2) S. aureus bloodstream infections (bacteremia), including those with right-sided infective endocarditis, caused by methicillin-susceptible and methicillin-resistant isolates. Combination therapy may be clinically indicated if the documented or presumed pathogens include gramnegative or anaerobic organisms [70].

Daptomycin shows poor oral bioavailability and can only be administered parenterally [71-76]. Dosing is based on the body weight of the patient. The currently recommended dose for skin and soft tissue infections is $4 \mathrm{mg} / \mathrm{kg}$ once daily and for right-sided endocarditis $6 \mathrm{mg} / \mathrm{kg}$ once daily. The once-daily dosing regimen could be shown to be better tolerated than previously investigated twice daily treatments. Myopathy was an adverse effect noted with twice daily dosing. Daptomycin has a very small volume of distribution of approximately $0.1 \mathrm{~L} / \mathrm{kg}$, one of the smallest volumes reported for any drug. This small volume indicates that there is very little tissue distribution and the majority of the drug remains in the blood stream and extracellular fluid space. The reason for the low volume of distribution is the drug's high plasma protein binding that has been reported to be $92 \%$ [76]. This high plasma protein binding always needs to be considered when comparing daptomycin plasma concentrations with their respective MIC values. As mentioned earlier, microdialysis is an appropriate technique to monitor the unbound, active drug concentrations in tissues. For localized tissue infections, drug concentrations in the interstitial space are an important determinant of successful therapy. In the diabetic population, peripheral arterial disease may limit antibiotic penetration into the target tissue. In a recent study, the pharmacokinetic profiles of daptomycin in the interstitial fluid of soft tissues were compared in diabetic and healthy volunteers by using in vivo microdialysis [77]. Twelve subjects (six diabetic and six healthy) received a single 4 $\mathrm{mg} / \mathrm{kg}$ dose of daptomycin intravenously. The degree of tissue penetration, defined as the ratio of the area under the free drug concentration-time curve for tissue to that for plasma, was similar. Daptomycin at $4 \mathrm{mg} / \mathrm{kg}$ penetrated well into the soft tissue, reaching concentrations approximately 70 to $90 \%$ of those of the free drug in plasma. Moreover, these free, bioactive concentrations in tissue exceeded the MICs for staphylococci and streptococci over the 24-h dosing interval.

However, the small volume of distribution of daptomycin shows that the majority of the drug resides in the plasma due its high plasma protein binding and that the respective tissue binding is much less. Daptomycin is not an appropriate choice for intracellular infections.

Caused primarily by gram-positive pathogens such as $S$. aureus and, to a lesser extent, E. faecalis, bone and joint infections are difficult to treat successfully. In a recent analysis, the outcome of treating bone and joint infections with daptomycin was evaluated [78]. Early clinical investigation of daptomycin in bone and joint infections unresponsive to antibiotics, such as vancomycin, showed a cure rate of approximately 80 $\%$, with a low incidence of adverse events and drug resistance. The authors concluded that daptomycin may be a promising option for patients with bone and joint infections such as MRSA osteomyelitis.

The half life of daptomycin is approximately 8 hours $[75,76,79,80]$. The reason for this long half-life is the restricted glomerular filtration due to the high protein binding. On the other hand, this long half-life facilitates the possibility of a once-daily dosing regimen. Approximately $60 \%$ of the dose is eliminated unchanged in the urine. As expected, patients with impaired renal function show longer half-lives and require longer dosing intervals. Patients with end-stage 
renal disease or an estimated creatinine clearance of $40 \mathrm{ml} / \mathrm{min}$ or below require a dosage adjustment of 4 $\mathrm{mg} / \mathrm{kg}$ once every $48 \mathrm{~h}$.

\section{COMPARISON OF THE PHARMACOKINETIC PROPERTIES}

The four compounds that are compared in this report are used for the treatment of MRSA and otherwise difficult to control infections. It is important to realize that their pharmacokinetic properties vary vastly and that they cannot be simply used interchange- ably. Table 1 compares the most relevant pharmacokinetic properties of these compounds.

The first major difference between these compounds is their oral bioavailability. Only linezolid can be administered orally, whereas vancomycin, daptomycin and tigecycline are limited to parenteral use. Once in the body, they show very different disposition. Daptomycin has a very small volume of distribution of $7 \mathrm{~L}$ indicating very little tissue distribution whereas tigecycline has a volume of distribution of 350-500 L. Vancomycin and linezolid are in-between with volumes of distribution of approximately 30 and

Table 1. Approved indications and pharmacokinetic properties of vancomycin, linezolid, tigecycline and daptomycin $[4,25,46,70]$.

\begin{tabular}{|c|c|c|c|c|}
\hline & Vancomycin & Linezolid & Tigecycline & Daptomycin \\
\hline $\begin{array}{l}\text { Approved } \\
\text { Indications (FDA) }\end{array}$ & $\begin{array}{l}\text { Serious or severe } \\
\text { infections caused by } \\
\text { susceptible strains of } \\
\text { methicillin-resistant } \\
\text { (beta-lactam-resistant) } \\
\text { staphylococci. } \\
\text { Alone or in } \\
\text { combination with an } \\
\text { aminoglycoside for } \\
\text { endocarditis caused } \\
\text { by S. viridans or } \\
\text { S. bovis. } \\
\text { For endocarditis } \\
\text { caused by } \\
\text { enterococci (e.g., } \\
\text { E. faecalis) only in } \\
\text { combination with an } \\
\text { aminoglycoside. }\end{array}$ & $\begin{array}{l}\text { Vancomycin- } \\
\text { Resistant E. faecium } \\
\text { infections } \\
\text { Nosocomial } \\
\text { pneumonia caused } \\
\text { by } S \text {. aureus or } \\
\text { S. pneumoniae } \\
\text { including multi-drug } \\
\text { resistant strains } \\
\text { Complicated skin } \\
\text { and skin structure } \\
\text { infections, including } \\
\text { diabetic foot } \\
\text { infections } \\
\text { Uncomplicated skin } \\
\text { and skin structure } \\
\text { infections caused by } \\
\text { MSSA or } \\
\text { S. pyogenes. } \\
\text { Community- } \\
\text { acquired pneumonia } \\
\text { caused by MSSA }\end{array}$ & $\begin{array}{l}\text { Complicated skin } \\
\text { and skin structure } \\
\text { infections. } \\
\text { Complicated intra- } \\
\text { abdominal } \\
\text { infections. } \\
\text { Community- } \\
\text { acquired bacterial } \\
\text { pneumonia }\end{array}$ & $\begin{array}{l}\text { Complicated skin } \\
\text { and skin structure } \\
\text { infections. } \\
\text { S. aureus } \\
\text { bloodstream } \\
\text { infections } \\
\text { (bacteremia), } \\
\text { including those with } \\
\text { right-sided infective } \\
\text { endocarditis, caused } \\
\text { by methicillin- } \\
\text { susceptible and } \\
\text { methicillin-resistant } \\
\text { isolates. }\end{array}$ \\
\hline
\end{tabular}

\begin{tabular}{|c|c|c|c|c|}
\hline Oral Bioavailability & Not absorbed & Not absorbed & Not absorbed & Completely absorbed \\
\hline Clearance & $0.06 \mathrm{~L} / \mathrm{h} / \mathrm{kg}$ & $0.01 \mathrm{~L} / \mathrm{h} / \mathrm{kg}$ & $0.33 \mathrm{~L} / \mathrm{h} / \mathrm{kg}$ & $0.10 \mathrm{~L} / \mathrm{h} / \mathrm{kg}$ \\
\hline Volume of Distribution & 0.3 to $0.43 \mathrm{~L} / \mathrm{kg}$ & $0.1 \mathrm{~L} / \mathrm{kg}$ & 8-9 L/kg & $0.7-0.8 \mathrm{~L} / \mathrm{kg}$ \\
\hline Half-Life & $4-6 h$ & $8 \mathrm{~h}$ & $27-42 \mathrm{~h}$ & $4-5 \mathrm{~h}$ \\
\hline Protein Binding & $55 \%$ & $90-93 \%$ & $71-89 \%$ & $31 \%$ \\
\hline $\begin{array}{l}\text { Major Route of } \\
\text { Elimination }\end{array}$ & renal & renal & biliary & $\begin{array}{l}\text { metabolism } \\
30 \% \text { renal }\end{array}$ \\
\hline Tissue Penetration & moderate & low & very high & high \\
\hline $\begin{array}{l}\text { Usual Dosing } \\
\text { Regimen }\end{array}$ & $\begin{array}{l}1000 \mathrm{mg} \text { IV } \\
\text { over } 60 \mathrm{~min} . \\
\text { Q12h } \\
\text { with Drug Level } \\
\text { Monitoring }\end{array}$ & $\begin{array}{l}\text { 4-6 mg/kg IV } \\
\text { over } 30 \mathrm{~min} . \\
\text { Q24h }\end{array}$ & $\begin{array}{l}50 \mathrm{mg} \text { IV } \\
\text { over } 30-60 \mathrm{~min} . \\
\mathrm{Q} 12 \mathrm{~h} \\
\text { First dose } 100 \\
\text { mg IV }\end{array}$ & $\begin{array}{l}600 \mathrm{mg} \text { IV } \\
\text { over 30-120 min. } \\
\text { Q12h } \\
400-600 \mathrm{mg} \text { PO } \\
\text { Q12h }\end{array}$ \\
\hline $\begin{array}{l}\text { Dosing in Renal } \\
\text { Impairment }\end{array}$ & $\begin{array}{l}\text { Increased Dosing } \\
\text { Interval with } \\
\text { Drug Level } \\
\text { Monitoring }\end{array}$ & $\begin{array}{l}\text { Increased Dosing } \\
\text { Interval }\end{array}$ & $\begin{array}{l}\text { No dose } \\
\text { adjustment }\end{array}$ & $\begin{array}{l}\text { No dose } \\
\text { adjustment }\end{array}$ \\
\hline
\end{tabular}


$50 \mathrm{~L}$, close to total body water. As far as drug elimination, daptomycin and vancomycin are mainly eliminated into the urine, whereas tigecycline is eliminated into the bile and linezolid is metabolized. Although these pathways are very different, the resulting half-lives of linezolid, vancomycin, and daptomycin are not greatly different and vary from 4-8 h. Tigecycline, however, has a much longer half-life of up to 1-2 days due to the slow redistribution from tissue binding sites. The four drugs also differ in their affinity to bind to proteins: Daptomycin has the highest protein binding with over $90 \%$, whereas vancomycin $(55 \%)$ and particularly linezolid (31\%) show much lower binding. Tigecycline binding is also high $(70-90 \%)$ featuring a highly unusual inversed nonlinearity with higher unbound fractions at lower concentrations. The degree of protein binding is clinically relevant since only the unbound drug is related to anti-infective activity. In terms of the pharmacodynamic properties the four candidate drugs also differ greatly: Daptomycin is a rapid killer with bactericidal activity whereas the other three provide much slower kill rates. Daptomycin and tigecycline are both concentration-dependent antibiotics indicating that high peak concentration will lead to increased anti-infective activity. Furthermore, for both drugs it has been shown that also the total daily dose (as measured by the area under the curve) correlates with therapeutic outcome. However, both drugs show very different safety profiles. High peak concentrations of tigecycline are not well tolerated so that in spite of its long half-life the total daily dose for tigecycline is administered BID. In case of daptomycin it could be shown that extending the dosing interval from twice daily to once-daily minimized the incidence of myopathy so that daptomycin is administered oncedaily. Both linezolid and vancomycin are administered BID in order to maintain sufficiently high trough concentrations. Vancomycin trough concentrations also correlate with its nephrotoxicity so that they can be monitored to minimize safety issues. For twice daily dosing, a trough target range of $15-20 \mu \mathrm{g} / \mathrm{mL}$ for microorganisms with a MIC $>1 \mu \mathrm{g} / \mathrm{mL}$ is recommended to exceed the desired AUC/MIC ratio of 400 and minimize toxicity. No drug level monitoring is required for any of the other three compounds.

So, in summary, one needs to take into account the respective pharmacokinetic and pharmacodynamic properties when using each of the four compounds discussed in order to maximize the chance for a successful therapeutic use. One can only hope that there will be more efficacious antimicrobial choices available in the not too far future since new resistance developments will certainly challenge our current antibiotic arsenal.

\section{REFERENCES}

1. Aston, J.L., M.J. Dortch, L.A. Dossett, C.B. Creech, and A.K. May, Risk factors for treatment failure in patients receiving vancomycin for hospital-acquired methicillinresistant Staphylococcus aureus pneumonia. Surg Infect (Larchmt), 2010. 11(1): p. 21-8.

2. Rybak, M.J., S.N. Leonard, K.L. Rossi, C.M. Cheung, H.S. Sader, and R.N. Jones, Characterization of vancomycin-heteroresistant Staphylococcus aureus from the metropolitan area of Detroit, Michigan, over a 22 -year period (1986 to 2007). J Clin Microbiol, 2008. 46(9): p. 2950-4.

3. Panday, P.N. and M. Sturkenboom, Continuous infusion of vancomycin less effective and safe than intermittent infusion, based on pharmacodynamic and pharmacokinetic principles. Clin Infect Dis, 2009. 49(12): p. 1964-5; author reply 1965.

4. FDA. Vancomycin Prescribing Information. 11/20/2010]; Available from:

http:/ / www.accessdata.fda.gov/drugsatfda_docs / label/2009/050671s014lbl.pdf.

5. Appelbaum, P.C., MRSA--the tip of the iceberg. Clin Microbiol Infect, 2006. 12 Suppl 2: p. 3-10.

6. Appelbaum, P.C., Reduced glycopeptide susceptibility in methicillin-resistant Staphylococcus aureus (MRSA). Int J Antimicrob Agents, 2007. 30(5): p. 398-408.

7. Deresinski, S., Counterpoint: Vancomycin and Staphylococcus aureus--an antibiotic enters obsolescence. Clin Infect Dis, 2007. 44(12): p. 1543-8.

8. Moise, P.A., G. Sakoulas, A. Forrest, and J.J. Schentag, Vancomycin in vitro bactericidal activity and its relationship to efficacy in clearance of methicillin-resistant Staphylococcus aureus bacteremia. Antimicrob Agents Chemother, 2007. 51(7): p. 2582-6.

9. Rybak, M., B. Lomaestro, J.C. Rotschafer, R. Moellering, Jr., W. Craig, M. Billeter, J.R. Dalovisio, and D.P. Levine, Therapeutic monitoring of vancomycin in adult patients: a consensus review of the American Society of Health-System Pharmacists, the Infectious Diseases Society of America, and the Society of Infectious Diseases Pharmacists. Am J Health Syst Pharm, 2009. 66(1): p. 82-98.

10. Roberts, J.A. and J. Lipman, Antibacterial dosing in intensive care: pharmacokinetics, degree of disease and pharmacodynamics of sepsis. Clin Pharmacokinet, 2006. 45(8): p. 755-73.

11. Moise-Broder, P.A., A. Forrest, M.C. Birmingham, and J.J. Schentag, Pharmacodynamics of vancomycin and other antimicrobials in patients with Staphylococcus aureus lower respiratory tract infections. Clin Pharmacokinet, 2004. 43(13): p. 925-42.

12. Scheetz, M.H., R.G. Wunderink, M.J. Postelnick, and G.A. Noskin, Potential impact of vancomycin pulmonary distribution on treatment outcomes in patients with methicillin-resistant Staphylococcus aureus pneumonia. Pharmacotherapy, 2006. 26(4): p. 539-50.

13. Georges, H., O. Leroy, S. Alfandari, B. Guery, M. Roussel-Delvallez, C. Dhennain, and G. Beaucaire, Pulmonary disposition of vancomycin in critically ill patients. Eur J Clin Microbiol Infect Dis, 1997. 16(5): p. 385-8.

14. Berthoin, K., E. Ampe, P.M. Tulkens, and S. Carryn, Correlation between free and total vancomycin serum concentrations in patients treated for Gram-positive infections. Int J Antimicrob Agents, 2009. 34(6): p. 55560.

15. Jeffres, M.N., W. Isakow, J.A. Doherty, P.S. McKinnon, D.J. Ritchie, S.T. Micek, and M.H. Kollef, Predictors of mortality for methicillin-resistant Staphylococcus aureus health-care-associated pneumonia: specific evaluation of vancomycin pharmacokinetic indices. Chest, 2006. 130(4): p. 947-55.

16. Tobin, C.M., J.M. Darville, A.H. Thomson, G. Sweeney, J.F. Wilson, A.P. MacGowan, and L.O. White, Vancomycin therapeutic drug monitoring: is there a consensus view? The results of a UK National External Quality Assessment Scheme (UK NEQAS) for Antibiotic Assays questionnaire. J Antimicrob Chemother, 2002. 50(5): p. $713-8$.

17. Hidayat, L.K., D.I. Hsu, R. Quist, K.A. Shriner, and A. Wong-Beringer, High-dose vancomycin therapy for me- 
thicillin-resistant Staphylococcus aureus infections: efficacy and toxicity. Arch Intern Med, 2006. 166(19): p. 2138-44.

18. Lodise, T.P., N. Patel, B.M. Lomaestro, K.A. Rodvold, and G.L. Drusano, Relationship between initial vancomycin concentration-time profile and nephrotoxicity among hospitalized patients. Clin Infect Dis, 2009. 49(4): p. 507-14

19. Mouton, J.W., U. Theuretzbacher, W.A. Craig, P.M. Tulkens, H. Derendorf, and O. Cars, Tissue concentrations: do we ever learn? J Antimicrob Chemother, 2008. 61(2): p. 235-7.

20. Muller, M., A. dela Pena, and H. Derendorf, Issues in pharmacokinetics and pharmacodynamics of anti-infective agents: distribution in tissue. Antimicrob Agents Chemother, 2004. 48(5): p. 1441-53.

21. Brunner, M., H. Derendorf, and M. Muller, Microdialysis for in vivo pharmacokinetic/pharmacodynamic characterization of anti-infective drugs. Curr Opin Pharmacol, 2005. 5(5): p. 495-9.

22. Schmidt, S., R. Banks, V. Kumar, K.H. Rand, and H. Derendorf, Clinical microdialysis in skin and soft tissues: an update. J Clin Pharmacol, 2008. 48(3): p. 351-64.

23. Skhirtladze, K., D. Hutschala, T. Fleck, F. Thalhammer, M. Ehrlich, T. Vukovich, M. Muller, and E.M. Tschernko, Impaired target site penetration of vancomycin in diabetic patients following cardiac surgery. Antimicrob Agents Chemother, 2006. 50(4): p. 1372-5.

24. Manfredi, R., Update on the appropriate use of linezolid in clinical practice. Therapeutics and Clinical Risk Management, 2006. 2: p. 455-464.

25. Pfizer. Zyvox Prescribing Information. 11/20/2010]; Available from: http://www.pfizerpro.com/hcp/zyvox.

26. Di Paolo, A., P. Malacarne, E. Guidotti, R. Danesi, and M. Del Tacca, Pharmacological issues of linezolid: an updated critical review. Clin Pharmacokinet, 2010. 49(7): p. 439-47.

27. Brier, M.E., D.J. Stalker, G.R. Aronoff, D.H. Batts, K.K. Ryan, M. O'Grady, N.K. Hopkins, and G.L. Jungbluth, Pharmacokinetics of linezolid in subjects with renal dysfunction. Antimicrob Agents Chemother, 2003. 47(9): p. 2775-80

28. Stein, G.E. and E.M. Wells, The importance of tissue penetration in achieving successful antimicrobial treatment of nosocomial pneumonia and complicated skin and soft-tissue infections caused by methicillin-resistant Staphylococcus aureus: vancomycin and linezolid. Curr Med Res Opin, 2010. 26(3): p. 571-88.

29. Dehghanyar, P., C. Burger, M. Zeitlinger, F. Islinger, F. Kovar, M. Muller, C. Kloft, and C. Joukhadar, Penetration of linezolid into soft tissues of healthy volunteers after single and multiple doses. Antimicrob Agents Chemother, 2005. 49(6): p. 2367-71.

30. Traunmuller, F., M.V. Schintler, S. Spendel, M. Popovic, O. Mauric, E. Scharnagl, and C. Joukhadar, Linezolid concentrations in infected soft tissue and bone following repetitive doses in diabetic patients with bacterial foot infections. Int J Antimicrob Agents, 2010. 36(1): p. 84-6.

31. Thallinger, C., C. Buerger, N. Plock, S. Kljucar, S. Wuenscher, R. Sauermann, C. Kloft, and C. Joukhadar, Effect of severity of sepsis on tissue concentrations of linezolid. J Antimicrob Chemother, 2008. 61(1): p. 1736.

32. Buerger, C., N. Plock, P. Dehghanyar, C. Joukhadar, and C. Kloft, Pharmacokinetics of unbound linezolid in plas$\mathrm{ma}$ and tissue interstitium of critically ill patients after multiple dosing using microdialysis. Antimicrob Agents Chemother, 2006. 50(7): p. 2455-63.

33. Barbour, A., F. Scaglione, and H. Derendorf, Class-dependent relevance of tissue distribution in the interpretation of anti-infective pharmacokinetic/pharmacody- namic indices. Int J Antimicrob Agents, 2010. 35(5): p. 431-8.

34. Jones, R.N., S. Kohno, Y. Ono, J.E. Ross, and K. Yanagihara, ZAAPS International Surveillance Program (2007) for linezolid resistance: results from 5591 Grampositive clinical isolates in 23 countries. Diagn Microbiol Infect Dis, 2009. 64(2): p. 191-201.

35. Jones, R.N., T.R. Fritsche, H.S. Sader, and J.E. Ross, LEADER surveillance program results for 2006: an activity and spectrum analysis of linezolid using clinical isolates from the United States (50 medical centers). Diagn Microbiol Infect Dis, 2007. 59(3): p. 309-17.

36. Locke, J.B., G. Morales, M. Hilgers, C.K. G, S. Rahawi, J. Jose Picazo, K.J. Shaw, and J.L. Stein, Elevated Linezolid Resistance in Clinical cfr-Positive Staphylococcus aureus Isolates Is Associated with Co-Occurring Mutations in Ribosomal Protein L3. Antimicrob Agents Chemother, 2010. 54(12): p. 5352-5.

37. Mendes, R.E., L.M. Deshpande, M. Castanheira, J. DiPersio, M.A. Saubolle, and R.N. Jones, First report of cfr-mediated resistance to linezolid in human staphylococcal clinical isolates recovered in the United States. Antimicrob Agents Chemother, 2008. 52(6): p. 2244-6.

38. Arias, C.A., M. Vallejo, J. Reyes, D. Panesso, J. Moreno, E. Castaneda, M.V. Villegas, B.E. Murray, and J.P. Quinn, Clinical and microbiological aspects of linezolid resistance mediated by the cfr gene encoding a $23 \mathrm{~S}$ rRNA methyltransferase. J Clin Microbiol, 2008. 46(3): p. 892-6.

39. Sanchez Garcia, M., M.A. De la Torre, G. Morales, B. Pelaez, M.J. Tolon, S. Domingo, F.J. Candel, R. Andrade, A. Arribi, N. Garcia, F. Martinez Sagasti, J. Fereres, and J. Picazo, Clinical outbreak of linezolid-resistant Staphylococcus aureus in an intensive care unit. JAMA, 2010. 303(22): p. 2260-4.

40. Petersen, P.J., N.V. Jacobus, W.J. Weiss, P.E. Sum, and R.T. Testa, In vitro and in vivo antibacterial activities of a novel glycylcycline, the 9-t-butylglycylamido derivative of minocycline (GAR-936). Antimicrob Agents Chemother, 1999. 43(4): p. 738-44.

41. Wilcox, M.H., Tigecycline and the need for a new broadspectrum antibiotic class. Surg Infect (Larchmt), 2006. 7(1): p. 69-80.

42. Gales, A.C. and R.N. Jones, Antimicrobial activity and spectrum of the new glycylcycline, GAR-936 tested against 1,203 recent clinical bacterial isolates. Diagn Microbiol Infect Dis, 2000. 36(1): p. 19-36.

43. Kenny, G.E. and F.D. Cartwright, Susceptibilities of Mycoplasma hominis, M. pneumoniae, and Ureaplasma urealyticum to GAR-936, dalfopristin, dirithromycin, evernimicin, gatifloxacin, linezolid, moxifloxacin, quinupristin-dalfopristin, and telithromycin compared to their susceptibilities to reference macrolides, tetracyclines, and quinolones. Antimicrob Agents Chemother, 2001. 45(9): p. 2604-8.

44. Bouchillon, S.K., D.J. Hoban, B.M. Johnson, J.L. Johnson, A. Hsiung, and M.J. Dowzicky, In vitro activity of tigecycline against 3989 Gram-negative and Grampositive clinical isolates from the United States Tigecycline Evaluation and Surveillance Trial (TEST Program; 2004). Diagn Microbiol Infect Dis, 2005. 52(3): p. 1739.

45. Gales, A.C., H.S. Sader, and T.R. Fritsche, Tigecycline activity tested against 11808 bacterial pathogens recently collected from US medical centers. Diagn Microbiol Infect Dis, 2008. 60(4): p. 421-7.

46. Pfizer. Tygacil Prescribing Information. 11/20/2010]; Available from: http://www.pfizerpro.com/hcp/tygacil.

47. Goedecke, V.A., C. Clajus, O. Burkhardt, J. MartensLobenhoffer, S.M. Bode-Boger, J.T. Kielstein, and M. Hiss, Pharmacokinetics and dialysate levels of dapto- 
mycin given intravenously in a peritoneal dialysis patient. Scand J Infect Dis, 2009. 41(2): p. 155-7.

48. Muralidharan, G., M. Micalizzi, J. Speth, D. Raible, and S. Troy, Pharmacokinetics of tigecycline after single and multiple doses in healthy subjects. Antimicrob Agents Chemother, 2005. 49(1): p. 220-9.

49. Conte, J.E., Jr., J.A. Golden, M.G. Kelly, and E. Zurlinden, Steady-state serum and intrapulmonary pharmacokinetics and pharmacodynamics of tigecycline. Int J Antimicrob Agents, 2005. 25(6): p. 523-9.

50. Ong, C.T., C.P. Babalola, C.H. Nightingale, and D.P. Nicolau, Penetration, efflux and intracellular activity of tigecycline in human polymorphonuclear neutrophils (PMNs). J Antimicrob Chemother, 2005. 56(3): p. 498501.

51. Barbour, A., S. Schmidt, B. Ma, L. Schiefelbein, K.H. Rand, O. Burkhardt, and H. Derendorf, Clinical pharmacokinetics and pharmacodynamics of tigecycline. Clin Pharmacokinet, 2009. 48(9): p. 575-84.

52. Crandon, J.L., M.A. Banevicius, and D.P. Nicolau, Pharmacodynamics of tigecycline against phenotypically diverse Staphylococcus aureus, in 48th Annual ICAAC/IDSA 46th Annual Meeting. 2008: Washington D.C.

53. Bulik, C.C., D.E. Wiskirchen, A. Shepard, C.A. Sutherland, J.L. Kuti, and D.P. Nicolau, Tissue penetration and pharmacokinetics of tigecycline in diabetic patients with chronic wound infections described by using in vivo microdialysis. Antimicrob Agents Chemother, 2010. 54(12): p. 5209-13.

54. Chin, T.F. and J.L. Lach, Drug diffusion and bioavailability: tetracycline metallic chelation. Am J Hosp Pharm, 1975. 32(6): p. 625-9.

55. Gabler, W.L., Fluxes and accumulation of tetracyclines by human blood cells. Res Commun Chem Pathol Pharmacol, 1991. 72(1): p. 39-51.

56. Rubino, C.M., L. Ma, S.M. Bhavnani, J. Korth-Bradley, J. Speth, E. Ellis-Grosse, K.R. Rodvold, P.G. Ambrose, and G.L. Drusano, Evaluation of tigecycline penetration into colon wall tissue and epithelial lining fluid using a population pharmacokinetic model and Monte Carlo simulation. Antimicrob Agents Chemother, 2007. 51(11): p. 4085-9.

57. Muralidharan, G., R.J. Fruncillo, M. Micalizzi, D.G. Raible, and S.M. Troy, Effects of age and sex on singledose pharmacokinetics of tigecycline in healthy subjects. Antimicrob Agents Chemother, 2005. 49(4): p. 16569 .

58. Hoffmann, M., W. DeMaio, R.A. Jordan, R. Talaat, D. Harper, J. Speth, and J. Scatina, Metabolism, excretion, and pharmacokinetics of [14C]tigecycline, a first-in-class glycylcycline antibiotic, after intravenous infusion to healthy male subjects. Drug Metab Dispos, 2007. 35(9): p. 1543-53.

59. Rodvold, K.A., M.H. Gotfried, M. Cwik, J.M. KorthBradley, G. Dukart, and E.J. Ellis-Grosse, Serum, tissue and body fluid concentrations of tigecycline after a single $100 \mathrm{mg}$ dose. J Antimicrob Chemother, 2006. 58(6): p. 1221-9.

60. Sun, H.K., C.T. Ong, A. Umer, D. Harper, S. Troy, C.H. Nightingale, and D.P. Nicolau, Pharmacokinetic profile of tigecycline in serum and skin blister fluid of healthy subjects after multiple intravenous administrations. Antimicrob Agents Chemother, 2005. 49(4): p. 1629-32.

61. Zimmerman, J.J., D.M. Harper, K. Matschke, J.L. Speth, D.G. Raible, and R.J. Fruncillo, Absence of an interaction between tigecycline and digoxin in healthy men. Pharmacotherapy, 2007. 27(6): p. 835-44.

62. Schwartz, J.B., The current state of knowledge on age, sex, and their interactions on clinical pharmacology. Clin Pharmacol Ther, 2007. 82(1): p. 87-96.
63. Troy, S.M., G. Muralidharan, and M. Micalizzi, The effects of renal disease on the pharmacokinetics of tigecycline (GAR-936), in 43rd Interscience Conference on Antimicrobial Agents and Chemotherapy. 2003, American Society for Microbiology: Chicago.

64. Meagher, A.K., P.G. Ambrose, T.H. Grasela, and E.J. Ellis-Grosse, The pharmacokinetic and pharmacodynamic profile of tigecycline. Clin Infect Dis, 2005. 41 Suppl 5: p. S333-40.

65. Raible, D.G., J.J. Zimmerman, D.M. Harper, and J.L. Speth, Pharmacokinetics and pharmacodynamics of tigecycline and warfarin coadministered to healthy subjects, in Interscience Conference on Antimicrobial Agents and Chemotherapy. 2005, American Society of Microbiology: Washingtn, DC.

66. Agwuh, K.N. and A. MacGowan, Pharmacokinetics and pharmacodynamics of the tetracyclines including glycylcyclines. J Antimicrob Chemother, 2006. 58(2): p. 25665.

67. van Ogtrop, M.L., D. Andes, T.J. Stamstad, B. Conklin, W.J. Weiss, W.A. Craig, and O. Vesga, In vivo pharmacodynamic activities of two glycylcyclines (GAR-936 and WAY 152,288) against various gram-positive and gramnegative bacteria. Antimicrob Agents Chemother, 2000. 44(4): p. 943-9

68. Lefort, A., M. Lafaurie, L. Massias, Y. Petegnief, A. Saleh-Mghir, C. Muller-Serieys, D. Le Guludec, and B. Fantin, Activity and diffusion of tigecycline (GAR-936) in experimental enterococcal endocarditis. Antimicrob Agents Chemother, 2003. 47(1): p. 216-22.

69. Silverman, J.A., N.G. Perlmutter, and H.M. Shapiro, Correlation of daptomycin bactericidal activity and membrane depolarization in Staphylococcus aureus. Antimicrob Agents Chemother, 2003. 47(8): p. 2538-44.

70. Cubist. Cubicin Prescribing Information. 11/20/2010]; Available from: http://www.cubicin.com/.

71. Abdel-Rahman, S.M., D.P. Benziger, R.F. Jacobs, H.S. Jafri, E.F. Hong, and G.L. Kearns, Single-dose pharmacokinetics of daptomycin in children with suspected or proved gram-positive infections. Pediatr Infect Dis J, 2008. 27(4): p. 330-4.

72. Dvorchik, B. and D. Damphousse, Single-dose pharmacokinetics of daptomycin in young and geriatric volunteers. J Clin Pharmacol, 2004. 44(6): p. 612-20.

73. Dvorchik, B.H. and D. Damphousse, The pharmacokinetics of daptomycin in moderately obese, morbidly obese, and matched nonobese subjects. J Clin Pharmacol, 2005. 45(1): p. 48-56.

74. Liang, S.H., W.H. Sheng, Y.T. Huang, F.L. Wu, and S.C. Chang, Pharmacokinetics and safety of multiple intravenous doses of daptomycin in a Taiwanese adult population. Chemotherapy, 2009. 55(2): p. 91-6.

75. Woodworth, J.R., E.H. Nyhart, Jr., G.L. Brier, J.D. Wolny, and H.R. Black, Single-dose pharmacokinetics and antibacterial activity of daptomycin, a new lipopeptide antibiotic, in healthy volunteers. Antimicrob Agents Chemother, 1992. 36(2): p. 318-25.

76. Dvorchik, B.H., D. Brazier, M.F. DeBruin, and R.D. Arbeit, Daptomycin pharmacokinetics and safety following administration of escalating doses once daily to healthy subjects. Antimicrob Agents Chemother, 2003. 47(4): p. 1318-23.

77. Kim, A., L.A. Suecof, C.A. Sutherland, L. Gao, J.L. Kuti, and D.P. Nicolau, In vivo microdialysis study of the penetration of daptomycin into soft tissues in diabetic versus healthy volunteers. Antimicrob Agents Chemother, 2008. 52(11): p. 3941-6.

78. Rice, D.A. and L. Mendez-Vigo, Daptomycin in bone and joint infections: a review of the literature. Arch Orthop Trauma Surg, 2009. 129(11): p. 1495-504.

79. Wise, R., T. Gee, J.M. Andrews, B. Dvorchik, and G. 
Marshall, Pharmacokinetics and inflammatory fluid penetration of intravenous daptomycin in volunteers. Antimicrob Agents Chemother, 2002. 46(1): p. 31-3.

80. Dvorchik, B., R.D. Arbeit, J. Chung, S. Liu, W. Knebel, and H. Kastrissios, Population pharmacokinetics of daptomycin. Antimicrob Agents Chemother, 2004. 48(8): p. 2799-807.
Received: November 17, 2010 / Accepted: November 22,2010

Address for correspondence:

Hartmut Derendorf

*100494, College of Pharmacy

1600 SW Archer Road, P3-27

Gainesville, FL 32610

USA

Phone: $352-273-7856$

Fax: 352-392-3249

E-mail: hartmut@ufl.edu 